\title{
LA VIDA Y LA MUERTE \\ ANTE LA ÉTICA Y EL DERECHO, PATERNALISMO MÉDICO Y DESARROLLO CIENTÍFICO
}

\section{La vida y la muerte ante la ética y el derecho}

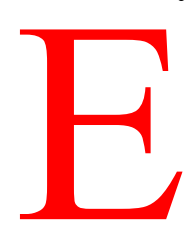

1 desarrollo de las ciencias biológicas está planteando no sólo interrogantes muy concretos sobre el tratamiento ético y jurídico de la vida y de la muerte, sino una necesidad de volver a filosofar sobre la vida y sobre la muerte. Quizá haya un camino de ¡da y vuelta que deba ser recorrido: ir de los casos concretos a los principios e ir de los principios a los casos concretos. Nunca se sabrá cuál método es mejor. En cualquier caso, me parece positivo hacer algunas breves reflexiones sobre una filosofía de la vida y de la muerte y al mismo tiempo analizar algunos interrogantes más concretos que hoy se presentan ante la ética y el derecho a causa de ese desarrollo de las ciencias biológicas, concretamente las ciencias biosanitarias.

Ante el «espectáculo» de la «posible posibilidad» científica de crear artificialmente un individuo humano, de producir individuos idénticos o de prolongar artificial y casi indefinidamente la vida, hay una primera idea que debiera destacarse para obviar ambiciones éticas y jurídicas inútiles: la vida y la muerte son un misterio, son realidades innegables que están ahí, pero que nadie ha conseguido explicar definitivamente. Nadie ha logrado responder de manera definitiva las grandes preguntas sobre qué son, por qué son y para qué son la vida y la muerte. Estamos en presencia de esa clase de realidades que colocan a la razón humana ante lo que Karl Jaspers llamaba «situaciones-límite» (Grenz-Situationen), esto es, ante preguntas que no tienen respuestas definitivas, como son también el dolor o la injusticia en el mundo. Ante esta clase de preguntas, la teoría y la práctica humanas deben ser enormemente humildes.

Sin embargo, se ha pensado y se ha escrito mucho sobre la vida y sobre la muerte. No se puede vivir e incluso no se puede morir, de un modo discretamente humano, sin haber tomado una posición ante 
la vida y la muerte. Frente a la vida y la muerte hay siempre -se quiera o no se quiera- toda una concepción del mundo, toda una filosofía. Como también se podría afirmar en sentido inverso lo siguiente: la filosofía se ha construido muchas veces pensando sobre la vida y sobre la muerte, esto es, los interrogantes de la vida y de la muerte han obligado al hombre a filosofar. José Ferrater Mora escribió hace ya años que el tema de la muerte era una ocasión para filosofar, para construir toda una ontología y una filosofía de la persona ${ }^{1}$.

En cualquier caso, una reflexión sobre la vida y de la muerte no puede reducirse a nivel meramente descriptivo, sino que inevitablemente implica preguntarse sobre el «deber ser» de la vida y de la muerte. En otras palabras: la vida y la muerte no pueden desligarse de una perspectiva ética y jurídica. Más aún: cuando la vida está amenazada de manera inmediata por la enfermedad e incluso por la muerte, no bastan las respuestas científicas. Grandes interrogantes morales y jurídicos rodean al ser humano que sufre una grave enfermedad o que está en las antesalas de la muerte. Sus familiares, sus amigos y los profesionales de la medicina que le atienden también tienen que dar y darse respuestas. La moral y el derecho son interpelados de modo radical por la vida que se hunde en la enfermedad incurable, en el dolor insportable o en las mismas oscuridades de la muerte. Todas las profesiones humanas están siempre interpeladas por la moral y el derecho, pero sin duda unas en mayor medida que otras. La excepcionalidad de un trabajo que trata con la vida en situaciones tan extremas o simplemente con la muerte es incuestionable. De este modo el trabajo del personal sanitario adquiere un inevitable dramatismo, aunque esa singularidad sea al mismo tiempo su grandeza, pues puede ser ocasión para realizar otras virtudes o valores humanos. Qué debe hacerse (moral o jurídicamente) ante la vida amenazada por la enfermedad o ante la proximidad de la muerte tiene difíciles respuestas.

La complejidad ética y jurídica del trabajo del personal sanitario es, pues, evidente y se complica más aún en el contexto de una sociedad enormemente desarrollada en el plano científico y técnico. El desarrollo extraordinario de las ciencias biomédicas plantea hoy todavía más interrogantes éticos y jurídicos a las profesiones sanitarias que en otras épocas. Está claro, por ejemplo, que la medicina del siglo XIX no tenía las posibilidades científicas para prologar la vida de una persona de que hoy se dispone y, por consiguiente, el personal sanitario no tenía que hacer frente a la pregunta de hasta cuándo se puede sostener artificialmente la vida de una persona.

${ }^{1}$ J. Ferrater Mora, «Ser y muerte», en Obras Selectas, t. II, Madrid, Ed. Revista de Occidente, 1967, págs. 297-298. 
Ahora bien, cualquiera que sean las respuestas científicas, morales o jurídicas que en el ámbito de la medicina puedan encontrarse, individual o colectivamente, me parece que el referente fundamental de toda actividad sanitaria ha de ser la vida como valor primario. Particularmente las respuestas a los problemas ético-jurídicos que puedan plantearse ante la práctica, de la medicina deberán estar conectadas con la «super-vivencia», con la continuidad en la vida. La humanidad no es un club de suicidas. En general, parece razonable apostar -en principio en el ámbito moral y jurídico- más por la vida que por la muerte, esto es, parece más razonable favorecer la vida que promover su extinción. En este sentido lleva razón Ronald Dworkin, cuando sostiene que es «una especie de vergüenza cósmica, el hecho de que la vida humana en cualquier estadio se extinga deliberadamente» ${ }^{2}$.

Aunque esta idea me parece clara, debo indicar también que la vida, aunque es un valor primario, no es un valor absoluto. La vida tiene que merecer la pena ser vivida. La vida humana no es pura inercia vegetativa. Se necesitan condiciones objetivas de diversa naturaleza y la esperanza de que determinados proyectos pueden ser cumplidos para que la vida pueda ser tenida como un valor digno de ser conservado, por lo menos para un sujeto que es racional, autoconsciente y libre. Insisto: la vida no es un valor absoluto que existe en sí y para sí, sino que existe en relación a otros valores, a lo que el ser humano puede darles mayor importancia o prioridad, como puede ser la libertad, también valor primario y tampoco absoluto. Hay gentes que prefieren morir a vivir sin libertad. Incluso hay instituciones sociales, como los ejércitos, que están destinados a matar si es necesario para defender otros valores, como la libertad y la independencia de un pueblo. La vida y la libertad pueden, pues, contradecirse y no hay respuestas absolutas a sus contradicciones. El aborto y la eutanasia son dos casos que muestran que la vida no es un valor absoluto, aunque se basen en dos concepciones de la vida y de la muerte muy discutibles.

En cualquier caso, como decía al principio, no hay una sola respuestas moral y tampoco jurídica a qué son y cómo deben ser la vida y la muerte.

\section{EI paternalismo médico: un test ético-jurídico para la vida y la muerte}

La importancia de estos planteamientos genéricos se agrava también

\footnotetext{
${ }^{2}$ R. Dworkin, El dominio de la vida. Una discusión acerca del aborto, la eutanasia y la libertad individual, Barcelona, Ed. Ariel, 1994, pág. 22.
} 
y especialmente en el campo de la medicina, porque se está tratando con la vida y con la muerte de los demás. No es que yo me responda a mí mismo sobre lo que es o debe ser la vida y la muerte para mí. En medicina «se juega» con la vida y la muerte ajenas. Pero hay un dato objetivo y destacado en el ámbito sanitario que conviene destacar: la vida ajena ha estados sometida a un «paternalismo médico» que está siendo revisado. El mismo hecho concreto de que la medicina tenga hoy enormes posibilidades de prolongar la vida cuestiona viejos principios y plantea nuevos problemas. Así se pregunta de modo directo si esas nuevas posibilidades de prolongar la vida se dan siempre en beneficio de los pacientes.

No cabe duda de que en las sociedades contemporáneas está todavía vigente un cierto e inevitable «paternalismo legal» sobre la salud y la vida, como lo demuestran las exigencias legales sobre cinturones de seguridad, venta de drogas, vacunaciones obligatorias, políticas sanitarias de alimentos, alcohol y tabaco. Este paternalismo se basa en la idea de que un limitado incremento de la libertad lleva a producir «liberticidas». El gran crítico del paternalismo fue J. S. Mill con su famosa obra «On Liberty» (1859). El paternalismo significa negativamente coaccionar o limitar la libertad de una persona en razón de su propio bien, interés o bienestar. Positivamente el paternalismo es un modo de intervención sobre la libertad ajena para evitar el daño a otros. Quizá el gran argumento a favor de todo paternalismo en este ámbito sea que al hacerse daño a sí mismo se haga daño a otros o a un interés colectivo ${ }^{3}$.

Pues bien, dentro de este contexto, según Heta Häyry, el paternalismo médico, esto es, el control de la vida de las gentes, presumiblemente en su propio interés, es el común denominador de la medicina y de las políticas sanitarias. El principio o el supuesto de que se parte es que «el médico sabe siempre qué es mejor», esto es, se convierte en una «autoridad epistémica» (epistemic authority), esto es, una autoridad científica. Sin embargo, según Häyry, la vida y la muerte, la salud y la enfermedad plantean siempre cuestiones «extraepistémicas». El patemalismo se apoya -dice Häyry- en la idea de que todo (pinchar, dar medicinas, operar, etc.) se hace «en beneficio del enfermo» de acuerdo con el código hipocrático.

No obstante, en su opinión, hay muchas ambigüedades en torno a esta cuestión ${ }^{4}$ y sobre todo hay muchas cuestiones fundamentales de indudable naturaleza filosófica. Por ejemplo, según Häyry, hay una cuestión de fondo que es la misma concepción de la vida y la muerte.

${ }^{3}$ Heta Häyry, The Limits of Medical Paternalism, London. Routledge, 1991, págs. 17-20.

${ }^{4}$ Häyry, H., The Limits of Medical Paternalisin, op. cit., pág. 2. 
El paternalismo radical, está fundado en la concepción de que la vida es una cosa buena y la muerte es el fin de una cosa buena, luego es un mal. Consecuentemente es irracional desear un mal. La vida es un regalo de Dios y tiene que ser respetado desde su comienzo natural hasta su final natural. Los médicos se constituyen en jueces del bien, de la racionalidad, de la moralidad del enfermo ${ }^{5}$.

Otra gran cuestión de fondo que replantea la crisis del paternalismo es cuál deba ser el fin de la medicina o del tratamiento médico. Habría que preguntarse si la medicina tiene fines objetivos, como pudiera ser maximizar la salud o prolongar la vida. De todos modos este tipo de problemas que se refieren a la determinación de fines y valores de una práctica humana de esta clase no puede realizarse con una metodología estrictamente científica. La determinación de los fines y valores a los que ha de servir la medicina depende -entre otras cosas- de una serie de opciones que debe realizar -también e indudablemente- el paciente, aunque no sólo el paciente. La medicina no puede venir impuesta al paciente.

Actualmente se entiende que la autodeterminación individual del paciente es un valor importante que condiciona la toma de decisiones o que exige su participación en los tratamientos médicos ${ }^{6}$. Todo tratamiento médico, al menos en unos niveles graves o críticos, debe estar acompañado de un cierto consentimiento del paciente, un consentimiento que debe ser «informado, voluntario y competente». Dado que lo que siempre está en juego es la vida y la muerte de una persona, el paciente como persona, en tanto que pueda, tiene algo importante que decir sobre cómo tratar su vida y su muerte. Es lógico, pues, que el «consentimiento informado» sea un elemento nuevo que cambia la ética en el tema de la prolongación de la vida frente al paternalismo hasta ahora dominante ${ }^{7}$.

Así pues, hay un principio fundamental que limita el paternalismo, que es -sostiene Häyry- lo que se ha llamado el «consentimiento informado» (informed consent). Esto es, no se puede intervenir sobre el enfermo sin su consentimiento informado, porque un consentimiento sin información implica la negación del derecho de la autonomía. Como también puede haber daño a ese derecho, si los médicos no explican bien la intervención, con el lenguaje necesario y sencillo. «Un médico no puede tratar a un paciente sin haberle explicado el riesgo y los hechos materiales que se refieren al tratamiento y sus alternativas, incluyendo el no-tratamiento y haya conseguido

${ }^{5}$ Häyry, H., The Limits of Medical Paternalism, op. cit., págs. 12-14.

${ }^{6}$ Dan W. Brock, Life and Death. Philosophical Essays of biomedical Ethics, Cambridge University Press, 1993, pág. 2.

${ }^{7}$ Häyry, H., The Limits of Medical Paternalism, op. cit., pág. 146. 
el consentimiento competente, voluntario y comprensible del paciente» ${ }^{8}$. Uno de los problemas más graves es lo que ha de entender el paciente, esto es, qué es lo que hay que explicarle y si mucho o poco. Y para cumplir con tal exigencia hay que tener en cuenta el nivel emocional del enfermo para asimilar la información y tomar una decisión. Quizá se deba descubrir solamente aquello que el paciente espera razonablemente conocer para decidir? .

En cualquier caso hay dos ámbitos de problemas. Uno es, según Brock, el terreno de los «hechos», en el que el médico tiene un protagonismo como para determinar «lo que está ocurriendo» o «qué puede ocurrir». La diagnosis, la prognosis, los tratamientos alternativos, así como el no-tratamiento son cuestiones científicas y de experiencia sobre las que debe pronunciarse en primer lugar el médico. Otra cosa es a qué objetivos, finalidades o valores pueden servir los distintos tratamientos que de los hechos pudieran derivarse, cuestión en la que sin duda ya tendría que intervenir el paciente. Hay un problema y es que los médicos a veces no quieran, según sus concepciones morales, seguir los deseos del enfermo y pasan la decisión a otro médico.

A pesar de las exageraciones del paternalismo médico, algunos consideran que no se deben ir al extremo de considerar al médico casi como un enemigo, sino todo lo contrario: habría que ver al médico -sostiene Brock- como un «abogado del bienestar del paciente». Además la experiencia clínica demuestra que las opiniones de los enfermos sobre el tratamiento debido son frecuentemente irracionales, aunque los enfermos no sean incompetentes. Entonces el médico tiene la responsabilidad de ayudar a una mejor elección, o hacerle ver lo irracional de su elección ${ }^{10}$. La complejidad de la vida y la muerte, en estas situaciones críticas como son la enfermedad y las antesalas de la muerte, exige sin duda que las decisiones sean conjuntas.

En todo caso a los médicos les preocupa obviamente las dificultades de explicar todos los riesgos posibles, la incapacidad de los enfermos para entender esa información médica necesaria, la situación emocional en que se encuentra el enfermo, etc. Pero últimamente ha aumentado su preocupación por las posibles responsabilidades legales y por la forma de protegerse contra los riesgos civiles o penales que pudieran plantearse a causa de su intervención. Y para protegerse de estas responsabilidades legales, ceden a favor del respeto de la autonomía del paciente ${ }^{11}$.

${ }^{8}$ Häyry, H., The Limits of Medical Paternalism, op. cit., pág. 144.

${ }^{9}$ Häyry, H., The Limits of Medical Paternalism, op. cit., pág. 146.

${ }^{10}$ Brock, D. W., Life and Death, op. cit., pág. 5.

${ }^{11}$ Häyry, H., The Limits of Medical Paternalism, op. cit., pág. 144. 
Según Brock, la crisis del paternalismo se replantea de manera especial con la eutanasia, en el que se enfrentan los derechos del paciente y los derechos/deberes del médico. En su opinión, el problema del «mantenimiento» de la vida se enmarca dentro de la injusticia de matar o de la punibilidad de disponer de la vida. Plantea sobre todo el problema de si las personas tienen «un derecho moral a no ser matadas», tesis que Brock mantiene, y si en medicina hay forma de matar compatibles con el reconocimiento y respeto de este derecho. Aquí entran en conflicto dos concepciones éticas diferentes y alternativas. Una es la concepción «consecuencialista o utilitaria», que mira al beneficio o daño de los pacientes. Y la segunda es la que considera que hay «un deber moral básico de no disponer intencionadamente de una vida inocente». Parece como si Brock estuviera admitiendo que pudiera disponerse de una vida inocente, esto es, que estaría reconociendo implícitamente la pena de muerte, esto es, la muerte del no-inocente ${ }^{12}$. En cualquier caso, Brock está dentro del argumento que recientemente ha mantenido Ronald Dworkin de que la vida humana tiene un valor intrínseco e incluso sagrado. El término «sagrado» se aplica también al arte y a la literatura, como algo intrínsecamente valioso ${ }^{13}$. Las grandes pinturas son intrínsecamente valiosas, porque son maravillosas, no porque queramos verlas o no nos gusten ${ }^{14}$. «Algo es instrumentalmente importante si su valor depende de su utilidad, de su capacidad para ayudar a las personas a obtener alguna cosa que desean. El dinero y los medicamentos, por ejemplo, son sólo instrumentalmente valiosos». "Algo es intrínsecamente valioso, por el contrario, si su valor es independiente de lo que las personas quieren, disfrutan o necesitan, o de lo que es bueno para ellas» ${ }^{15}$.

Brock continúa su argumentación y afirma que es más importante la injusticia de matar que el principio moral de la autodeterminación. En este orden de cosas en medicina hay dos formas de «matar» a un enfermo. Una es matar cuando el enfermo ha renunciado a su derecho a no ser matado (eutanasia activa). Y otra es cuando el derecho a no ser matado es superado por consideraciones morales competentes (escasez o impotencia de los medios para mantener la vida). Sin embargo, hay quienes sostienen que no hay diferencia entre matar y dejar morir. Tal es el ejemplo que cuenta James Rachels: «Smith tiene un primo de seis años, del que heredará mucho dinero si muere. Una mañana Smith entra en el cuarto de baño y ahoga al niño.

${ }^{12}$ Brock, D. W., Life and Death, op. cit., pág, 6.

${ }^{13}$ Dworkin, R., El dominio de la vida, op. cit., pág. 98.

${ }^{14}$ Dworkin, R., El dominio de la vida, op. cit., pág. 98.

${ }^{15}$ Dworkin, R., El dominio de la vida, op. cit., pág. 97. 
Jones tiene un primo de seis años, del que heredará mucho dinero si muere. Jones plantea matar al niño. Una mañana al entrar en el cuarto de baño, observa que el niño se ha resbalado, se ha golpeado la cabeza y ha caído en la bañera. Jones permanece allí hasta que el niño se ahoga ${ }^{16}$. Brock está en contra de la tesis de que matar es en sí moralmente diferente de permitir que se muera. En la vida clínica concreta -dice Brock- el derecho del paciente (competente o incompetente) a sopesar los beneficios o cargas de los tratamientos alternativos tiene sus límites. Los médicos pueden permitir morir, pero no pueden matar (dar morfina para aliviar el dolor, pero no matar). En todo caso es difícil determinar la diferencia entre «lo permisible y lo no permisible» a la hora de disponer de la vida en medicina ${ }^{17}$.

En España se planteó el problema jurídico de «dejar morir»o de prestar asistencia médica contra la voluntad de los interesados con motivo de una huelga de hambre protagonizada por miembros del grupo terrorista Grapo. Una decisión del Juzgado de Vigilancia Penitenciaria y un Auto de la Sección Segunda de la Audiencia Provincial de Madrid les obligó a recibir asistencia médica y a recibir alimentación en contra de su voluntad. El Tribunal Constitucional en sus S. 120/1990 de 27 de junio, declara que la «intervención médica forzosa», por su importancia y valores que implica y por internarse en el campo de la axiología, suscita polémica doctrinal variada e irreconciliable. Pero, ateniéndose a criterios estrictamente constitucionales (FJ5), el Tribunal reconoce que hay un conflicto entre el supuesto derecho de la libertad a ocasionar incluso la propia muerte y el derecho-deber de la Administración penitenciaria de velar por la vida y la salud de los internos sometidos a su custodia (FJ6). El derecho a la vida tiene, según el Tribunal Constitucional, «un contenido de protección positiva (protección de la vida sin contar con la voluntad de sus titulares STC 53/1985) que impide configurarlo como un derecho de libertad que incluya el derecho a la propia muerte» (FJ7). El Tribunal Constitucional considera que «no es posible admitir que la Constitución garantice en su artículo 15 el derecho a la propia muerte y, por consiguiente, carece de apoyo constitucional la pretensión de que la asistencia médica coactiva es contraria a ese derecho constitucionalmente inexistente» (FJ7). No es lo mismo -añade el Tribunal Constitucional- asumir el riesgo de morir en un acto que sólo afecta al titular de esa vida, que asumir ese riesgo con el fin de conseguir que la

${ }^{16}$ James Rachels (1986), The End of the Life. Euthanasia and Morality, Oxford, New York, en Herline Pauer-Studer, «Peter Singer on Euthanasia», en The Monist, 1993, vol. 76, pág. 144.

${ }^{17}$ Brock, D. W., Life and Death, op. cit., p. 6. 
Administración deje de ejercer potestades que le confiere el ordenamiento jurídico (FJ7).

Un voto particular del magistrado Jesús Leguina Villa dice que si bien el derecho a la vida no puede ser confundido con un pretendido derecho a morir o a decidir sobre la propia muerte, ello no significa que no se tenga derecho a que nadie que no sea uno mismo decida e imponga coactivamente lo que haya de hacerse para conservar la salud, seguir viviendo o escapar al peligro de muerte; ni incluye el derecho a rechazar la ayuda o la asistencia sanitaria que no se desea ni se ha solicitado. También la Sentencia del Tribunal Constitucional 137/1990 de 19 de julio insiste en el argumento que el derecho a la vida (artículo 15 de la CE) tiene un contenido positivo y no incluye un derecho a la propia muerte. Cada persona puede disponer de su vida o disponer su propia muerte, pero esa disposición constituye sólo un acto que la ley no prohíbe y no un derecho subjetivo que la Administración ha de garantizar, más aun cuando en este caso -terroristas del Grapo encarcelados y en huelga de hambre- estaban en una relación especial con la Administración y en un marco legal que obliga a la Administración a velar por la vida y la salud de los internos sometidos a su custodia (FJ5).

De esta problemática quizá la conclusión más clara que puede sacarse es que nada está totalmente claro, esto es, que no hay una respuesta clara que permita caer de un modo radical ni del lado del paternalismo médico, ni tampoco del lado de una autonomía del paciente. Otra conclusión que puede obtenerse es que la vida clínica está rodeada de una peculiar paradoja. Por un lado, se puede constatar que la mayoría de las decisiones en los hospitales son bastantes normales y no requieren procedimientos especiales. Las situaciones o casos-límite no se están dando todos los días. Pero por otro lado, los profesionales de la medicina constatan que la vida médica real es más compleja y emocional que lo que pueden prever los principios morales e incluso las normas jurídicas. Häyry concluye un principio interesante, pero sin duda enormemente abstracto: «La única política general dentro de la medicina y del cuidado de la salud que es finalmente aceptable es la política de un moderado anti paternalismo, basado en el respeto de la libertad del paciente ${ }^{18}$.

\section{Las dimensiones éticas de las ciencias biológicas}

Una parte importante de los problemas éticos y jurídicos en el campo de la medicina surge a causa del avance de las ciencias biológicas,

${ }^{18}$ Häyry, H., The Limits of Medical Paternalism, op. cit., pág. 183. 
en especial la genética. Este avance ha sido en los últimos años espectacular. Estas ciencias se han introducido en niveles muy profundos sobre el origen y la manipulación de la vida. Lógicamente este desarrollo científico plantea interrogantes nuevos y en general replantea preguntas clásicas sobre la relación entre la ciencia, la ética y el derecho.

Las preocupaciones ético-jurídicas ante estos avances científicos tienen una primera fase, según Reiser, que se puede situar entre 1945-1966. La preocupación central estaba en torno al sujeto humano. El gran principio que se concluyó es que ningún sujeto humano, más aun después del Código de Nürenberg, se sometería a experimentos científicos sin su consentimiento y siempre que el experimento no le causare daño o muerte, y siempre con la posibilidad de retirar su consentimiento.

La segunda fase transcurre en 1966-1974, cuando se considera fundamental el compromiso social de los científicos de la biología. Es un momento en que preocupa que la investigación pueda afectar o amenazar a las poblaciones. Las instituciones democráticas podrían estar amenazadas por una élite científica. Los científicos ejercen un poder, cuyo alcance no se conocían totalmente, y además no se responsabilizaban de los efectos de su investigación (energía atómica, la bomba biológica, cambiar los sexos, modificaciones fundamentales por medio de trasplantes, manipular la memoria y los sentimientos, crear vida, etc.). Había una preocupación por las consecuencias de las ciencias biológicas y una exigencia de que los investigadores principales informaran a su equipo y a la opinión pública del azar de sus experimentos.

La tercera fase está entre 1975-1989, cuando se replantea más críticamente los procedimientos para generar y transmitir conocimientos dentro de las ciencias biológicas. Hay una mayor apertura de la sociedad hacia el discurso ético y una mayor autoconciencia colectiva de los científicos sobre las dimensiones morales de su trabajo y sobre su responsabilidad pública. A partir de la propuesta de delinear el genoma humano, en Estados Unidos ya se ha creado una «Guide for Contracts and Grants» por el NIH (National Institut of Health) en 1989, donde se exige que para conseguir fondos estatales hay que presentar un «programa de principios de integridad científica» e incluso a veces de un examen de los significados éticos del trabajo científico propuesto.

Puede hablarse incluso de una última fase, a partir de 1990, cuando se produce una intensificación e institucionalización del discurso ético, sobre todo en el campo de la investigación y de la educación científica. En Estados Unidos aparecen instituciones tales como las«Institutional Review Boards» (1974) y la «Office of 
Scientific Integrity» (1989), que quiere coordinar la intervención de las autoridades, de la sociedad y de los científicos para evaluar los métodos y objetivos de los proyectos científicos. Sin embargo, los científicos se quejan por las excesivas intromisiones estatales en su investigación. Bernard David de la «Harvard Medical School» escribe un artículo cuyo título refleja muy expresivamente esta preocupación: «How far should Big Brother's Hand reach?». De todos modos, debe reconocerse que dentro de las ciencias biológicas hay en general una mayor autorreflexión respecto a su responsabilidad pública y a los parámetros éticos de sus actividades ${ }^{19}$.

Indudablemente el avance espectacular de las ciencias biológicas replantea el problema de los límites y controles de la ciencia. Hay un supuesto metodológico y ético que no suele cuestionarse excesivamente en la actualidad: cualquier ciencia natural, más o menos directamente, implica en sus métodos, en sus objetos y en sus objetivos algunas interrogantes axiológicos. En la ciencia están inevitablemente implicadas cuestiones de valor. La ciencia tiene que saber que lo que es bueno para el individuo puede ser malo para el grupo social y que lo que es bueno para el grupo social puede ser malo para el individuo ${ }^{20}$. Las responsabilidades éticas y sociales de los científicos se centra en «manifestar los beneficios», porque la ciencia está pagada con fondos públicos y privados sobre la base de sus posibles beneficios sociales y en «advertir de los riesgos», como hicieron Einstein y Russell, pero precisando lo que son los hechos y lo que es su opinión ${ }^{21}$. En cualquier caso es indispensable que el científico tenga la libertad intelectual y científica para buscar la verdad y que no se vea sometido a exigencias de utilidad impuestas por una política o una religión. El gran problema ético del futuro es el «control del hombre sobre su propia evolución biológica». Los poderes de evolución biológica están ahora en manos de los científicos. Ahí está el reto. Un importante deber suyo será ver claramente la naturaleza de las alternativas, así como informar y demandar a la sociedad y a sus dirigentes una discusión de todos los problemas que impiden el crecimiento científico o la ampliación del poder humano ${ }^{22}$.

${ }^{19}$ Reiser, S. J., «The Ethics movements in the biological sciences: A new wave of discovery», en Ruth Ellen Bulgar, Elizabeth Hetiman y otros, The Ethical Dimensions of Biological Sciences, Cambridge, Cambridge University Pres., 1993, págs. 1-13.

${ }^{20}$ Glass, B., «The ethical basis of science», en Ruth Ellen Bulgar, Elizabeth Hetiman y otros, The Ethical Dimensions of Biological Sciences, Cambridge, Cambridge University Press, 1993, págs. 43-45.

${ }^{21}$ Glass, B.. «The ethical basis of science», op. cit., págs. 43-53.

${ }^{22}$ Glass, B., «The ethical basis of science», op. cit., págs. 53-54. 
En este sentido es particularmente importante constatar los interrogantes que se plantean ante los avances logrados, y que se adivinan en un futuro no muy lejano, por la genética. La investigación del genoma humano plantea hoy y planteará graves conflictos éticos y jurídicos. Particularmente preocupante por sus efectos sociales, y no sólo individuales, será el uso y el abuso de la información genética. El genoma humano nos permitirá conocer una gran cantidad del inventario genético de los individuos, como puede ser su propensión a las enfermedades. En muchos casos, la posibilidad (en algunos casos, la certeza) de una enfermedad se producirá con años e incluso décadas antes de que se disponga de un tratamiento efectivo para la enfermedad. No cabe duda que esta nueva situación planteará especiales problemas psicológicos y éticos. El test genético puede producir unos conflictos psicológicos masivos muy fuertes, porque no todo el mundo quiere conocer la consistencia y los riesgos de su salud por medio de un mapa genético. Además el test genético puede afectar a familiares y a terceras personas distintas del que desea conocer su test genético. Además están los problemas que plantearía también la llamada terapia genética, incluso una terapia genética que permitiría cambiar genéticamente un individuo. En alguna medida ya se puede cambiar genéticamente a los seres humanos con la biotecnología existente.

También la información genética planteará problemas de tipo social y jurídico. Debe reflexionarse sobre el alcance de esa información genética, ya que afecta o afectará a los descendientes no nacidos que no han dado su consentimiento para su elaboración. Por ello se está hablando ya del «derecho a la autonomía de las generaciones futuras», esto es, de su derecho a dejarles decidir lo que quieren ser y lo que quieren saber sobre sí mismos, aspectos fundamentales de la dignidad humana que puede poner en entredicho la ingeniería genética $^{23}$.

A nivel social, la ocupación o selección de un puesto de trabajo se podría ver afectada por el conocimiento del mapa genético disponible para evaluar las posibilidades o tendencias a tener unas determinadas enfermedades. Se podría llegar a hacer obligatorios los tests genéticos para conseguir un puesto de trabajo (workplace genetic testing).

También las compañías de seguros se mostrarían también muy interesadas en conocer esos test o mapas genéticos, porque trabajan bajo el principio de participar el riesgo. Cuando el riesgo es igualmente

${ }^{23}$ Lecaldano, E., «La bioetica e limiti del diritto», en Democrazia e diritto, 1988, vols. 4-5, dedicado a «Le nuove frontiere del diritto», pág. 40. 
incierto, todos pagan igual. En estos casos, pagarían menos los que tuvieran menos riesgos ${ }^{24}$.

Además, desde esta perspectiva socio-jurídica, la genética podría colaborar a dar una explicación de los comportamientos humanos y por tanto podría afectar a la responsabilidad ética y jurídica de los ciudadanos. Ya se ha dado establecido la relación entre el alcoholismo y la genética, como también se podrían explicar ciertos fenómenos de adicción, de enfermedades laborales, de tendencias educativas o profesionales de grupos y razas, etc. Incluso se podría plantear la cuestión de si las desigualdades económicas y educativas son causadas por desigualdades sociales y entonces la sociedad tendría la obligación de remediarlas, o bien las desigualdades son fruto de diferencias heredadas, por lo que no habría que preocuparse de las acciones propias que sean injustas ${ }^{25}$.

Así pues, las ciencias biológicas están hoy interpelando continuamente a la ética y el derecho. Hay que reconocer que el derecho va lentamente detrás de estos avances. De todos modos hoy existe en el mundo una importante legislación (nacional e internacional), sobre la protección de embriones, sobre participación en experiencias clínicas, fecundación asistida, fecundación artificial, transferencia de embriones, bancos de semen, tráfico de órganos, etc., que han puesto un poco de control y han condicionado la investigación científica de acuerdo con los intereses y las convicciones morales mayoritarias de una sociedad política concreta o de la misma sociedad internacional. Sin embargo, la vida científica y la experiencia clínica van mucho más de prisa que lo que las convicciones sociales y sobre todo la misma legislación pueden prever y concretar ${ }^{26}$.

Ahora bien, lo que está replanteando el avance de las ciencias biológicas es la vieja cuestión de los límites de la ciencia en relación a la ética y al derecho. Siempre que la ciencia llega a los límites donde empieza la imaginación humana, surgen los miedos y también más graves interrogantes éticos. Sobre todo surge la pregunta si la sociedad, por medio del Estado y del Derecho, debe intervenir en esta clase de investigaciones y hasta dónde debe intervenir. La respuesta no es fácil. En todo caso hay un dato que me parece incuestionable: la ciencia no opera en un vacío axiológico, porque tiene unos fines y unos valores a los que, implícita o explícitamente, sirve, y tampoco opera en un vacío económico, porque no se investiga

${ }^{24}$ Murray, Thomas H., «Ethical issues in human genome research.», op. cit., págs. 284-288.

${ }^{25}$ Murray, Thomas H., «Ethical issues in human genome research.», op. cit., págs. 289-292.

${ }^{26}$ R. Martín Mateo, Bioética y Derecho, Barcelona, Editorial Ariel, 1987. 
-y menos a estos niveles- a partir de un patrimonio personal, sino por medio de fondos de financiación de tal envergadura que, sean o no sean de titularidad pública, deben ser controlados públicamente por instancias democráticas en razón de la importancia de sus consecuencias sociales. Por ello no debe rechazarse en principio el control o la fijación de ciertos límites a la investigación científica, si fueren necesarios, desde la legitimidad de un Estado democrático de Derecho o de un orden jurídico internacional razonablemente democrático.

Pero, por otro lado, en principio y por principio, se debe ser enormemente respetuoso con la libertad científica, expresión concreta de la libertad de pensamiento, que no debe sentirse continuamente amenazada por la sospecha o por la posibilidad de unos efectos perversos. Desgraciadamente muchos de los grandes progresos de la humanidad se han hecho desde una libertad científica que se ha tenido que enfrentar a un sistema social, jurídico y político que no estaba dispuesto a consentirle sus experiencias o sus innovaciones («aventuras») científicas.

Se debe reconocer que es muy difícil concretar unos criterios para armonizar el control democrático de la ciencia y la libertad científica, si bien hay un dato que no debe olvidarse: las ciencias se desarrollan bajo el impulso de poderes que no siempre son visibles. En este sentido, mi propuesta sobre los límites de las ciencias biológicas es «la publicidad» sobre cómo, para qué y con qué medios técnicos y financieros se «hace ciencia» y de quién son esos medios. Esa publicidad podrá servir para que órganos efectivamente representativos de los intereses generales de la humanidad y de las sociedades políticas particulares establezcan los marcos legales, y no sólo éticos, dentro de los cuales han de desarrollarse esas ciencias biológicas.

El espectacular desarrollo de las ciencias biomédicas está replanteando la contradicción entre la libertad individual (en este caso, la libertad científica) y los intereses generales de la humanidad como especie y de su contorno natural. Esta contradicción no tiene síntesis perfectas, sino salidas ambivalentes, que pretenderán servir al mismo tiempo a la protección de los intereses generales y a la misma libertad científica. En determinados momentos y casos esas leyes controlarán y restringirán la libertad científica, pero en otros momentos y casos las leyes serán más permisivas y la humanidad tendrá que correr unos riesgos si quiere ser respetuosa con la libertad científica, que no sólo es una exigencia de la dignidad humana, sino una fuente decisiva para el progreso y el bienestar de la humanidad. No todo lo que es científica y técnicamente posible puede permitirse, pero tampoco todo lo que la libertad individual 
pueda imaginar o crear puede impedírse. Este es el juego duro y a veces dramático en el que están insertos los investigadores científicos y las instituciones estatales e internacionales democráticas. 
$\triangle$ 